\title{
SUDDEN DISAPPEARANCE OF MORELS AT THE PAS, MANITOBA
}

\author{
WALTER KRIVDA, Box 864, The Pas, Manitoba. R9A 1 K8
}

The morel is famous in Europe as a table delicacy. In The Pas it has been picked by Ukrainian people since the 1920's. A gourmet friend pronounces it the best of all mushrooms. In Paris, France six morels cooked in their own juice and laid on a plate command a price of $\$ 30.00$. At The Pas for many years we have picked them by the shopping bag full. Indeed it is rumoured that some 30 shopping bags full were picked from a particular area by ten people last May and early June. They occurred in poplar and willow woods - with most poplars of the diameter of a man's wrist. The leaves were just greening on the trees producing the effect of filtered light. They grew abundantly averaging 6 to the square meter over a 4 acre area. This year not a single morel was to be found where formerly they were in arrayed thousands. At least three distinct species were present. It has been suggested that the sudden onset of winter in early fall last year failed to allow the morel mycelium to develop and mature to overwinter properly. It would be valuable and interesting to observe this in future years - if in fact an early winter spoils the morel crop the following spring.

A student informs me that the reason why there are no morels is because we have had no spring thunder storms yet. There is a legend which states that it is thunder shaking up the ground which helps mushrooms (all kinds?) to grow! This is had on the good authority of an old woman who has picked morels for many years!



